OPEN ACCESS

Edited by:

Karin Loser,

University of Münster, Germany

Reviewed by:

Xinhua $Y u$,

Forschungszentrum Borstel (LG),

Germany

Yasuo Kitajima,

Gifu University, Japan

*Correspondence:

Hiroaki Iwata

hiroaki.iwata@med.hokudai.ac.jp

Specialty section:

This article was submitted to

Autoimmune and Autoinflammatory

Disorders,

a section of the journa

Frontiers in Immunology

Received: 16 November 2018

Accepted: 08 January 2019

Published: 24 January 2019

Citation:

Kamaguchi M and Iwata H (2019) The Diagnosis and Blistering Mechanisms of Mucous Membrane Pemphigoid.

Front. Immunol. 10:34.

doi: 10.3389/fimmu.2019.00034

\section{The Diagnosis and Blistering Mechanisms of Mucous Membrane Pemphigoid}

\author{
Mayumi Kamaguchi ${ }^{1,2}$ and Hiroaki Iwata ${ }^{1 *}$ \\ ${ }^{1}$ Department of Dermatology, Hokkaido University Graduate School of Medicine, Sapporo, Japan, ${ }^{2}$ Department of Oral \\ Diagnosis and Medicine, Hokkaido University Graduate School of Dental Medicine, Sapporo, Japan
}

Mucous membrane pemphigoid (MMP) is a mucous membrane-dominated autoimmune subepithelial blistering disease that is caused by autoantibodies against various autoantigens in basement membrane zone (BMZ) proteins, including collagen XVII (COL17). Clinicians face diagnostic problems in detecting circulating antibodies and targeted antigens in MMP. The diagnostic difficulties are mainly attributed to the low titers of MMP autoantibodies in sera and to heterogeneous autoantigens. Additionally, no unanimous diagnostic criteria have been drawn for MMP, which can result in delayed diagnoses or misdiagnoses. This review aims to integrate and present currently available data to clarify diagnostic strategies and to present diagnostic criteria for MMP. The ultimate blistering mechanism in MMP has not been elucidated, and such mechanism is especially obscure in COL17-type MMP. In bullous pemphigoid (BP), which is the most common autoimmune subepidermal blistering disease, some patients show oral lesion as well as predominant skin lesions. However, there is no fundamental explanation for the onset of oral lesions in BP. This article summarizes innovative research perspectives on the pathogenesis of oral lesions in pemphigoid. Finally, we propose a potential pathogenesis for COL17-type MMP.

Keywords: mucous membrane pemphigoid, type XVII collagen, direct immunofluorescence, collagen IV, C-terminas, steric hindrance

\section{INTRODUCTION}

Mucous membrane pemphigoid (MMP) refers to mucous membrane-dominated autoimmune subepithelial blistering diseases (1-4). MMP is caused by autoantibodies against various autoantigens in the basement membrane zone (BMZ), including collagen XVII (COL17, also called BP180) (5), BP230 (6), laminin 332 (7-9), integrin $\alpha 6 / \beta 4$ (10-12), and collagen VII (COL7) (13, 14). Of these, the C-terminus of COL17 and laminin 332 are thought to be major autoantigens for MMP. Autoantibodies against Integrin $\alpha$ 6/ק4 are associated with the occurrence of ocular lesions (15). Clinically, the most common site of involvement in MMP is the oral mucosa (80-90\%). Also involved are the ocular mucosa (50\%), the skin (20\%), the genital mucosa (15\%), the anal mucosa $(10 \%)$, and the pharynx, esophagus and larynx $(<10 \%)(16)$. In the oral cavity, the gingiva is most commonly affected (70\% of oral MMP cases), followed by the buccal mucosa $(60 \%)$, the palate (27\%), and the tongue and lips (13\%) (17).

MMP is relatively difficult to diagnose clinically, for several reasons that are documented in the next section. One reason is that the titer of autoantibodies is lower in MMP than in bullous pemphigoid $(\mathrm{BP})(18,19)$, which is the most common autoimmune skin blistering disease (2). 
Therefore, circulating autoantibodies are detected less frequently in MMP than in BP (17), which leads to challenges in diagnosing MMP.

The pathogenesis of MMP has been poorly understood to date. As for the mechanism of blister formation in autoimmune blistering disorders, the direct inhibition of protein-protein binding by autoantibodies in pemphigus (steric hindrance) (20, 21) and/or Fc-mediated complement and inflammatory cell activation in pemphigoid, including in epidermolysis bullosa acquisita, have been reported $(22,23)$. However, the mechanism of blister formation on the oral mucosa in pemphigoid remains undiscovered. Histologically, MMP patients tend to have fewer inflammatory findings than BP patients do (24). This may indicate differences in blistering mechanisms between MMP and BP.

This article focuses on diagnostic tips for improving the clinical diagnosis of MMP and proposes a possible pathomechanism for oral mucosa-specific blister formation that is related to less severe inflammatory mechanisms.

\section{ISSUES IN DIAGNOSING MMP}

To diagnose MMP, we perform several tests, including histological and immunological analyses. Histologically, the formation of junctional separations at the BMZ is observed in specimens from lesional mucosa $(25,26)$. However, histopathological examination is not always performed, particularly when the lesions are limited to the eyes due to the hesitation about performing conjunctival biopsies and the concern about scar formation. In addition, such examination does not always reveal subepithelial blisters, because of tissue destruction (27). Immunologically, the deposition of IgG autoantibodies and C3, or sometimes of IgA autoantibodies, at the BMZ can be detected by direct immunofluorescence (DIF) of lesional or perilesional samples $(1,28)$. To identify circulating autoantibodies to the BMZ, indirect immunofluorescence (IIF) with normal human skin as the substrate is usually performed, but autoantibodies are detected in only $17-53 \%$ of MMP cases (5, 17, 18, 29). According to the latest data from our hospital, in $22 \%(8 / 36)$ of cases, MMP autoantibodies (IgG) are detected by IIF with normal human skin. $1 \mathrm{M} \mathrm{NaCl}$-split skin IIF (ssIIF) is more sensitive than IIF. The staining of ssIIF with MMP sera produces linear IgG deposits in $58-82 \%$ of MMP cases on either the epidermal or the dermal side of the $\operatorname{BMZ}(17,30,31)$. Even though ssIIF might be helpful to differentiate autoantigens located on the epidermal side of the BMZ from those located on the dermal side of the BMZ by causing separation at the level of the lamina lucida, it does not definitively identify the autoantigens. Immunoblotting using epidermal or dermal extracts and recombinant antigenic polypeptides is useful

Abbreviations: MMP, mucous membrane pemphigoid; BMZ, basement membrane zone; COL17, collagen XVII; COL7, collagen VII; BP, bullous pemphigoid; DIF, direct immunofluorescence; IIF, indirect immunofluorescence; ssIIF, $1 \mathrm{M} \mathrm{NaCl}$-split skin IIF; ELISA, enzyme-linked immunosorbent assays; NC, non-collagenous; CLEIA, chemiluminescence enzyme immunoassay; DPP-4i, dipeptidyl peptidase-4 inhibitor; COL4, collagen IV. for identifying specific targeted autoantigens, although the techniques are not commonly available in routine examinations. Enzyme-linked immunosorbent assays (ELISAs) are widely used to detect autoantibodies directing specific autoantigens $(32,33)$. Approximately $85-96 \%$ of autoantibodies in BP are detected by commercially available COL17-NC16A ELISA or chemiluminescence enzyme immunoassay (CLEIA) systems (33-36). However, the antigens targeted by commercially available ELISA/CLEIA systems are limited to the certain domains on BMZ proteins, such as COL17 (NC16A), BP230 (N/C-terminus), and COL7 (NC1/NC2) (37). Due to the low titer and the heterogeneity of MMP autoantibodies, only 30-52\% of the autoantibodies in COL17-type MMP may be recognized using COL17 NC16A ELISA/CLEIA (17, 38, 39). Because of these problems, a certain share of MMP patients may not be diagnosed and treated.

\section{Diagnostic Points for MMP Structure-Maintaining Biopsy Technique for Hematoxylin and Eosin (H\&E) Staining}

Inadequate biopsy techniques and improper tissue handing can easily lead to the loss of the oral mucosal epithelia in samples from MMP patients. The destruction of oral mucosal tissue makes a diagnosis difficult. Endo et al. presented a "staband-roll" biopsy technique to maintain the gingival epithelia in desquamative gingivitis (40). This technique is designed to keep the epithelium from detaching from the biopsy specimen by reducing lateral forces during the procedure. In 52 patients with desquamative gingivitis, the epithelium was maintained in 12 of the 13 patients with MMP using this technique.

\section{Tissue-Bound Immunoglobulin and Complement}

In cases that are difficult to diagnose, DIF using the patient's tissue is a valuable test for diagnosing MMP. Shimanovich et al. showed that multiple and repeated biopsies increase the sensitivity of DIF (41). At the first workup, 69\% (36/52) of patients who underwent only 1 biopsy were found to be positive, whereas $85 \%$ $(22 / 26)$ of patients who underwent biopsies from more than 1 site were positive. Overall, 95\% (74/78) showed positive results in DIF after repeated biopsies. The same group demonstrated that immunohistochemistry for C3d or C4d is helpful in screening for cases of suspected MMP when paraffin-embedded tissue is available (42). Linear deposits of C3d or C4d were detected in $53 \%(18 / 34)$ or $59 \%(20 / 34)$ of patients, respectively. We also reported that DIF samples taken from non-lesional buccal mucosa by punch biopsy contribute to the diagnosis of MMP (27). In $7 \mathrm{MMP}$ with gingiva-dominant oral lesions, tissue-bound antibodies were detected in all cases. The buccal mucosa is easy to access, and punch biopsies provide well-maintained BMZ structures.

\section{Detection of Autoantibodies \\ Laminin 332-Type MMP}

Goletz et al. established a specific IIF assay using laminin 332-expressing human HEK293 cells for the detection of antilaminin 332 autoantibodies (43). Using BIOCHIP ${ }^{\circledR}$ mosaics, 
the laminin 332 heterotrimer recognized 77\% (72/93) of the anti-laminin 332 MMP sera. Several studies developed ELISA systems to detect autoantibodies against laminin 332. Bernard et al. presented a novel ELISA that uses purified laminin 332 from SCC25 cells and detected autoantibodies in $20.1 \%$ of MMP patients (44). Chiorean et al. showed that the results of an ELISA using purified or recombinant human laminin 332 correlated closely with those of immunoblotting in $36 \mathrm{MMP}$ cases (45).

\section{COL17-Type MMP}

Ali et al. demonstrated that salivary IgG and IgA antibodies against COL17-NC16A are equal to serum in diagnostic value (39). $45 \%(29 / 64)$ of whole saliva samples and $53 \%$ $(33 / 64)$ of serum samples were positive for IgG and/or IgA antibodies by COL17-NC16A ELISA. However, 50-70\% of MMP autoantibodies were found to mainly react with the C-terminus of COL17 instead of with the COL17-NC16A domain $(5,6,46)$. Immunoassays for the detection of autoantibodies against the entire extra domain of COL17 need to be provided. Schmidt et al. proposed an IF assay that uses Sf21 insect cells expressing full-length COL17 (47). The novel assay detected 84\% (6/7) of circulating autoantibodies in MMP sera. Recently Izumi et al. established a novel ELISA system using full-length human COL17 recombinant protein (full-length COL17 ELISA) (48). With the full-length COL17 ELISA, 9 of 12 MMP cases (75\%) showed positivity, whereas with the conventional COL17-NC16A ELISA and BP230 ELISA, 4 of 12 sera (42\%), and 3 of 12 sera $(25 \%)$ showed positivity, respectively. We reported on another unique concept that helped to overcome the difficulty of detecting MMP autoantibodies. IIF is usually performed using normal human skin, even though MMP mainly involves the mucosa and not the skin. We performed IIF tests using normal human oral mucosa (18). In $20 \mathrm{MMP}$ sera and $20 \mathrm{BP}$ sera, the sensitivities were compared by IIF using skin and mucosa. $85 \%$ (17/20) of the MMP sera reacted to mucosa, and $35 \%$ $(7 / 20)$ to skin. Immunoblotting using normal human epidermal keratinocytes (skin keratinocytes) and normal human oral mucosal keratinocyte lysates was able to detect autoantibodies. Skin and mucosal keratinocyte lysates reacted to a $180-\mathrm{kDa}$ protein corresponding to COL17 in $10 \%(2 / 20)$ and 55\% (11/20) of MMP sera, respectively.

Mucosal substrates (normal oral mucosa and normal oral mucosal keratinocytes) are beneficial for detecting autoantibodies and identifying autoantigens in MMP. However, it is more difficult to obtain oral mucosa than skin. To overcome this drawback, we attempted to immortalize the oral mucosal keratinocytes by using E6/E7 proteins of HPV (49). Cell lysates of immortalized mucosal keratinocytes effectively identified MMP autoantigens in 60\% (18/30) of MMP sera.

For the sensitive detection of COL17-NC16A-specific IgG, Emtenani et al. reported that normal human skin was superior to monkey esophagus. The monkey esophagus was able to detect only $17 \%(2 / 12)$ of COL17-NC16A antibodies, whereas skin detected $100 \%(12 / 12)$ of the antibodies (50). Together with the low homology of COL17-NC16A between human and monkey esophagus, these pieces of evidence suggest that the expression of COL17 protein differs by anatomical location, such as skin vs. mucosa. The use of suitable specimens for IIF from specific sites may contribute to the sensitive detection of autoantibodies in pemphigoid.

\section{Proposed Diagnostic Strategies}

The diagnostic criteria for MMP remain unclear. The lack of commonly recognized diagnostic criteria can result in delayed diagnoses or misdiagnoses. The international consensus has documented that the clinical findings of mucosa-dominant lesions and DIF detecting tissue-bound IgG, IgA, and/or C3 are essential for the diagnosis (1). Several studies have followed this criteria $(41,44,51)$. We also fundamentally agree with the criteria and have introduced it in our studies. However, in pure ocular pemphigoid, up to $20 \%$ of cases are negative in DIF $(52,53)$. Therefore, serological analyses detecting circulating autoantibodies and histological examinations are included in the diagnostic criteria in some studies $(39,52,54,55)$. To clarify MMP diagnosis, we here propose diagnostic criteria based on current knowledge. We emphasize the significance of serological analyses, especially in cases of DIF negativity (Figure 1). The diagnosis of MMP is confirmed when clinical criteria and DIF findings are fulfilled. In DIF-negative or DIF-unavailable (not performed) cases, at least one serological or histological finding is needed.

\section{THE EVIDENCE OF BLISTERING MECHANISMS FOR ORAL LESIONS IN PEMPHIGOID}

\section{Clinical Evidence of Mucosal Lesions in Pemphigoid}

Several pieces of evidence demonstrate associations between mucosal lesions and certain clinical features in pemphigoid. Kridin et al. reported that BP patients with normal eosinophil counts present mucous lesions more frequently than those with elevated eosinophil counts (56). In some patients with oral involvement, the administration of a dipeptidyl peptidase4 inhibitor (DPP-4i) is associated with BP onset (57). An association between MMP and the intake of DDP-4i was also reported (58). Furthermore, a certain HLA allele (HLADQB1*03:01) is associated with MMP occurrence (59-63). HLADQB1*03:01 is also related to a high risk of DDP-4i-associated BP (59). Hofmann et al. demonstrated that $56 \%$ of BP patients with mucosal involvement showed IgG reactivity against both the COL17-NC16A and C-terminus regions of COL17 (64). Clape et al. revealed that the absence of anti-BP230 autoantibodies was associated with the presence of mucosal lesions in $\mathrm{BP}(65)$.

\section{Experimental Evidence of MMP in vivo and in vitro}

In addition to the previous studies on mechanisms of blister formation in BP, several lines of evidence that partly explain the MMP pathogenesis have been demonstrated. 


\section{Diagnostic criteria for MMP}

Clinical manifestation

1) Tense blisters and/or erosions on the mucosa

\section{DIF}

(+) 2) Tissue-bound IgG and/or C3

$(-)$

Serological analysis

MMP

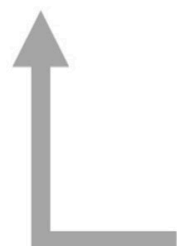

$(+)$

Anti-basement membrane autoantibodies detected by IIF, ssIIF, ELISA or immunoblotting

\section{and/or}

Histological analysis

$(+)$

\section{3-2) Subepidermal blister formation showed by H\&E staining}

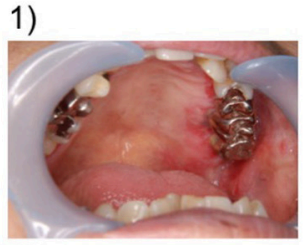

2)

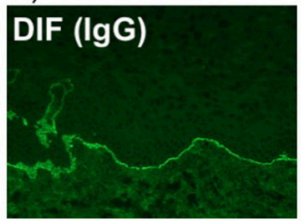

3-1)

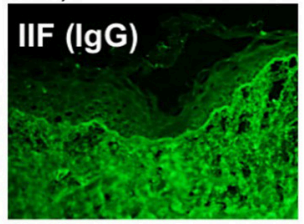

3-2)

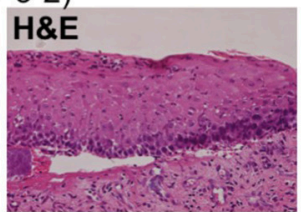

FIGURE 1 | Diagnostic strategy for MMP. The diagnosis of MMP is confirmed by clinical features and positive DIF results. In DIF-negative or DIF-unavailable cases, at least one serological or histological finding is needed. DIF, direct immunofluorescence; IIF, indirect immunofluorescence; ELISA, enzyme-linked immunosorbent assay; H\&E, hematoxylin and eosin staining.

\section{Laminin 332-Type MMP}

In 2017, Heppe et al. established a mouse model in which injected rabbit anti-laminin 332 IgG antibodies caused subepidermal blisters to develop in the ears, eyes and oral cavity of adult C57BL/6 mice (66). In this model, the clinical manifestations are $\mathrm{Fc}$ receptor-dependent and complement-dependent, similar to those of previous BP mouse models. Meanwhile, Lazarova et al. showed that injections with rabbit anti-human laminin $332 \mathrm{IgG}$ or Fab fragments induced subepithelial blisters in the skin of neonatal $\mathrm{BALB} / \mathrm{c}$ mice $(67,68)$. In this antibodytransfer model, C5-deficient or mast cell-deficient mice also exhibited subepidermal blisters on the skin (67). The same group established a human skin graft model that uses SCID mice (69). They noted that the injection of purified IgG from MMP patients or anti-human laminin 332 IgG resulted in non-inflammatory subepidermal blisters on the skin. These models from the latter group might define the pathomechanisms in MMP; however, the models lack predominant mucosal involvement.

\section{COL17-Type MMP}

Although experimental mouse models for laminin 332-type MMP have been established, in vivo studies on COL17-type MMP have not made progress. In previous studies of COL17-targeted mouse models for BP, oral lesions were not addressed and there was a lack of description, both clinically and histologically (70-73).

For the pathogenesis of COL17-type MMP in vitro, Imanishi et al. reported that some MMP IgGs targeting the C-terminus of COL17 showed the internalization of COL17 in both oral keratinocytes and DJM-1 cells (74), which are cells from a squamous cell carcinoma cell line (75). In contrast, other MMP IgGs against the C-terminus did not induce the internalization of COL17 thoroughly. The autoantibody-induced endocytosis of COL17 is thought to play an important role in pemphigoid blister formation $(76,77)$. However, it remains unclear why some MMP IgGs targeting the $\mathrm{C}$-terminus of COL17 show the internalization of COL17.

\section{POTENTIAL BLISTERING MECHANISMS IN THE ORAL MUCOSA IN PEMPHIGOID}

Even though COL17 is a major targeted antigen both in $\mathrm{BP}$ and MMP, the predominantly involved organs differ between these two diseases. The blister mechanisms in autoimmune subepidermal blistering diseases are complicated, 
but they are strongly associated with various factors, such as complement activation and inflammatory cell infiltrates $(78,79)$. In contrast, several lines of evidence have been reported regarding complement-independent blister formation in $\mathrm{BP}(80)$. Anti-COL17-NC16A antibodies induce the internalization and depletion of COL17 and lead to inadequate adhesion strength in keratinocytes (76). COL17 depletion is important for blistering along the lamina lucida without inflammation. We noticed that no research has addressed the pathomechanisms of oral lesions in both BP and MMP. Before addressing the possible pathogenesis of MMP, we first focus on blister formation in the oral mucosa in BP.

\section{The Blistering Mechanism in the Oral Mucosa in BP}

Recently, we gained new insight into the blister mechanism of oral lesions (81). We showed that COL17 expression is approximately $30-50 \%$ higher in mucosal keratinocytes than in skin keratinocytes, as confirmed by qPCR and immunoblotting analysis. This higher COL17 expression in mucosal keratinocytes is associated with stronger cell adhesion in such keratinocytes. The cell adhesion strength was found to be 50\% higher for mucosal keratinocytes than skin keratinocytes. Furthermore,
anti-COL17-NC16A antibodies induce significantly greater COL17 depletion in skin keratinocytes than in mucosal keratinocytes. This indicates that the higher expression of COL17 in mucosa may compensate for the COL17 depletion induced by pemphigoid IgG. In other words, the predominant skin blistering may relate to the residual amount of COL17 after BP-IgG induces COL17 depletion. This is similar to the blistering mechanism in pemphigus, in which desmoglein 1 and 3 compensate for each other in the oral mucosa and the skin. Potential blister formation in BP is initiated by the binding of autoantibodies to COL17, which leads to the internalization and depletion of COL17 from the plasma membrane. The depletion of COL17 may impair hemidesmosome formation and weaken the strength of adhesion to the basement membrane. Finally, separations may be caused by mechanical stress or inflammation induced via the $\mathrm{Fc}$ fragment of the pathogenic IgG. The lower frequency of oral lesions in BP may be attributed to the high expression level of COL17 in oral mucosa (Figure 2A). Additionally, we showed that IgG against the C-terminus of COL17 may have pathogenicity. The pathogenicity of $\operatorname{IgG}$ against regions outside the NC16A domain remains controversial in vivo and in vitro (74, $82,83)$. In our study, however, COL17 depletion was significantly enhanced by stimulation with a combination of IgGs against the NC16A domain and the C-terminus (Figure 2A). This evidence
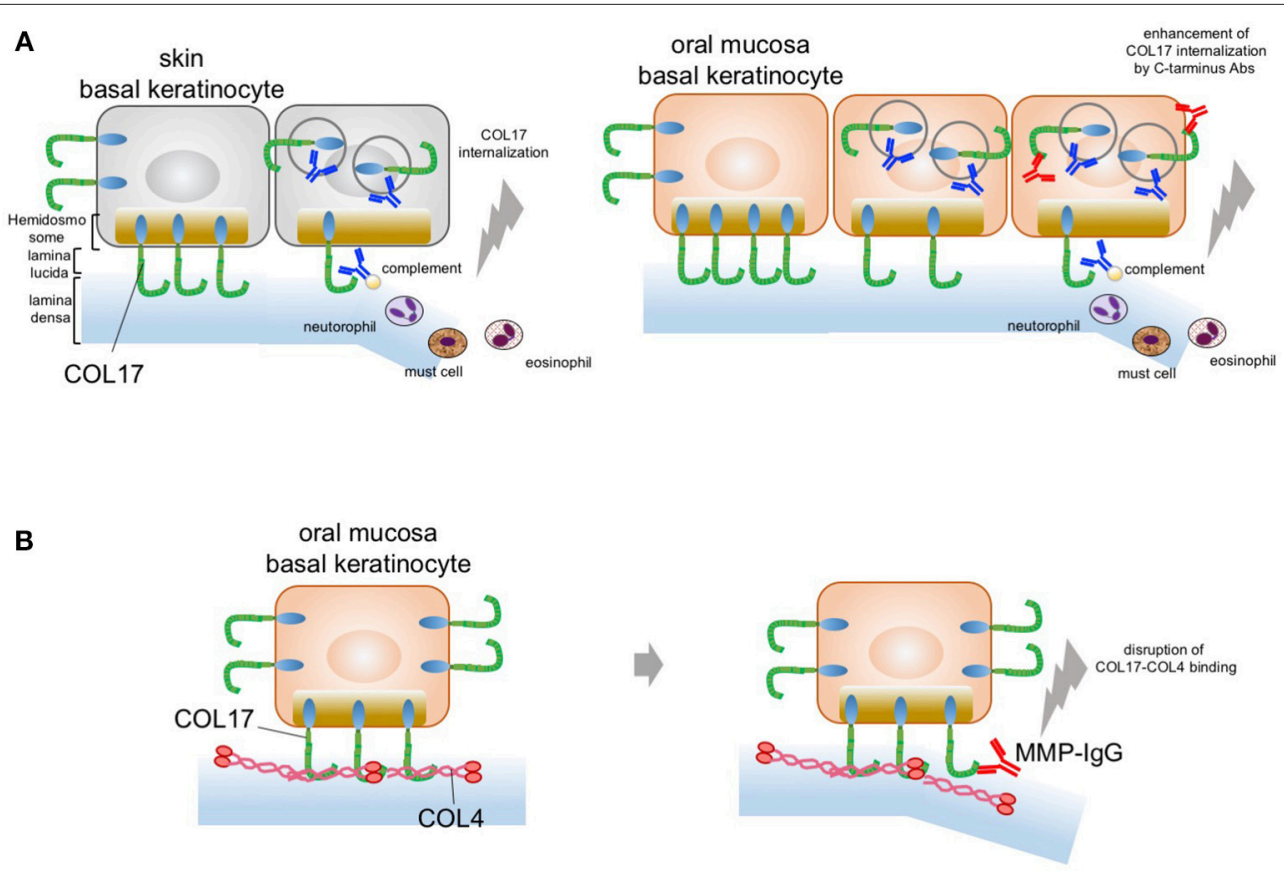

FIGURE 2 | Potential blistering mechanisms in oral mucosa. (A) The oral mucosal blistering in BP. COL17 molecules are located in both the hemidesmosomal and the non-hemidesmosomal plasma membranes. In the skin, autoantibodies targeting COL17-NC16A lead to the internalization of non-hemidesmosomal COL17 and result in COL17 depletion. The internalization and depletion of COL17 disturb the supply of hemidesmosomal COL17 and impair hemidesmosome formation. Eventually, intra-lamina lucida separation is caused by mechanical stress, complement activation, and/or inflammatory cell infiltration. This is mainly observed in the skin; therefore, the blisters predominantly occur in the skin (left panel). In the oral mucosa, autoantibodies targeting the C-terminus of COL17 enhance COL17 depletion induced by autoantibodies targeting COL17-NC16A. The blister formation in oral mucosa may be a result of the enhancement of COL17 depletion induced by autoantibodies targeting the C-terminus of COL17 in BP patients (right panel). (B) The predominant oral mucosal blistering in MMP. The direct binding of COL17 to COL4 is disrupted by lgG against the C-terminus in the oral mucosa. Autoantibodies in MMP targeting the C-terminus of COL17 inhibit the protein-protein interaction in the oral mucosa and reduce hemidesmosomal adhesion without the internalization of COL17. 
suggests that BP patients with IgG targeting not only the NC16A domain but also the C-terminus may show blisters in the skin and the mucosa. To support this, several studies demonstrated an association between autoantibodies to the C-terminus and mucosal lesions in BP $(64,84)$. Autoantibodies targeting the C-terminus are potentially pathogenic in certain cases of BP.

\section{MMP-Specific Blister Mechanism Without Inflammation}

Histologically, MMP patients have less severe inflammatory findings than BP patients do. The blistering mechanism of MMP may differ from that of BP. We recently found direct binding between collagen IV (COL4) and COL17 in skin and oral keratinocytes (24). Interestingly, this COL4-COL17 binding is disrupted by IgG against the C-terminus in oral keratinocytes. Furthermore, several MMP IgGs that target the C-terminus of COL17 were found to inhibit COL4-COL17 binding and to result in the reduction of hemidesmosomal adhesion (Figure 2B). That is, MMP-IgGs may directly disrupt COL4-COL17 binding and result in separation at the $\mathrm{BMZ}$ without inflammation.

As for the potential blistering mechanism of laminin 332-type MMP, Fc-dependent, and complement-dependent mechanisms have been revealed by using laminin 332-type mouse models. However, laminin 332 interacts with other BMZ molecules,

\section{REFERENCES}

1. Chan LS, Ahmed AR, Anhalt GJ, Bernauer W, Cooper KD, Elder $\mathrm{MJ}$, et al. The first international consensus on mucous membrane pemphigoid: definition, diagnostic criteria, pathogenic factors, medical treatment, and prognostic indicators. Arch Dermatol. (2002) 138:370-9. doi: 10.1001/archderm.138.3.370

2. Schmidt E, Zillikens D. Pemphigoid diseases. Lancet (2013) 381:320-32. doi: 10.1016/S0140-6736(12)61140-4

3. Murrell DF, Marinovic B, Caux F, Prost C, Ahmed R, Wozniak K, et al. Definitions and outcome measures for mucous membrane pemphigoid: recommendations of an international panel of experts. J Am Acad Dermatol. (2015) 72:168-74. doi: 10.1016/j.jaad.2014.08.024

4. Di Zenzo G, Carrozzo M, Chan LS. Urban legend series: mucous membrane pemphigoid. Oral Dis. (2014) 20:35-54. doi: 10.1111/odi.12193

5. Schmidt E, Skrobek C, Kromminga A, Hashimoto T, Messer G, Bröcker EB, et al. Cicatricial pemphigoid: IgA and IgG autoantibodies target epitopes on both intra- and extracellular domains of bullous pemphigoid antigen $180 \mathrm{Br}$ J Dermatol. (2001) 145:778-83. doi: 10.1046/j.1365-2133.2001.04471.x

6. Balding SD, Prost C, Diaz LA, Bernard P, Bedane C, Aberdam D, et al. Cicatricial pemphigoid autoantibodies react with multiple sites on the BP180 extracellular domain. J Invest Dermatol. (1996) 106:141-6. doi: 10.1111/1523-1747.ep12329728

7. Domloge-Hultsch N, Gammon WR, Briggaman RA, Gil SG, Carter WG, Yancey KB. Epiligrin, the major human keratinocyte integrin ligand, is a target in both an acquired autoimmune and an inherited subepidermal blistering skin disease. J Clin Invest. (1992) 90:1628-33. doi: 10.1172/JCI116033

8. Kirtschig G, Marinkovich MP, Burgeson RE, Yancey KB. Anti-basement membrane autoantibodies in patients with anti-epiligrin cicatricial pemphigoid bind the $\alpha$ subunit of laminin 5. J Invest Dermatol. (1995) 105:543-8. doi: 10.1111/1523-1747.ep12323431

9. Natsuga K, Nishie W, Shinkuma S, Moriuchi R, Shibata M, Nishimura $\mathrm{M}$, et al. Circulating $\operatorname{IgA}$ and $\operatorname{IgE}$ autoantibodies in antilaminin-332 mucous membrane pemphigoid. Br J Dermatol. (2010) 162:513-7. doi: 10.1111/j.1365-2133.2009.09508.x including COL17. Given our latest concept of MMP-specific blister formation, anti-laminin 332 antibodies may disrupt the molecular interactions of laminin 332, resulting in the predominance of mucosal blister formation in laminin 332-type MMP.

\section{CONCLUSION}

As highlighted in this review, we propose disease-specific diagnostic strategies for MMP. The pathogenesis of COL17-type MMP is distinct from that of BP and is more closely related to less inflammatory blister mechanisms due to the inhibition of COL4-COL17 binding or COL17 depletion.

\section{ETHICS STATEMENT}

The studies were conducted in accordance with the Helsinki Guidelines and were approved by the Ethics Committee of Hokkaido University.

\section{AUTHOR CONTRIBUTIONS}

All authors listed have made a substantial, direct and intellectual contribution to the work, and approved it for publication.

10. Tyagi S, Bhol K, Natarajan K, Livir-Rallatos C, Foster CS, Ahmed AR. Ocular cicatricial pemphigoid antigen: partial sequence and biochemical characterization. Proc Natl Acad Sci USA. (1996) 93:14714-9. doi: $10.1073 /$ pnas.93.25.14714

11. Bhol KC, Dans MJ, Simmons RK, Foster CS, Giancotti FG, Ahmed AR. The autoantibodies to alpha 6 beta 4 integrin of patients affected by ocular cicatricial pemphigoid recognize predominantly epitopes within the large cytoplasmic domain of human beta 4. J Immunol. (2000) 165:2824-9. doi: 10.4049/jimmunol.165.5.2824

12. Rashid KA, Gürcan HM, Ahmed AR. Antigen specificity in subsets of mucous membrane pemphigoid. J Invest Dermatol. (2006) 126:2631-6. doi: 10.1038/sj.jid.5700465

13. Cozzani E, Di Zenzo G, Calabresi V, Carrozzo M, Burlando M, Longanesi L, et al. Autoantibody profile of a cohort of 78 Italian patients with mucous membrane pemphigoid: correlation between reactivity profile and clinical involvement. Acta Derm Venerol. (2016) 96:768-73. doi: 10.2340/00015555-2311

14. Bieber $\mathrm{K}, \mathrm{Koga} \mathrm{H}$, Nishie $\mathrm{W}$. In vitro and in vivo models to investigate the pathomechanisms and novel treatments for pemphigoid diseases. Exp Dermatol. (2017) 26:1163-70. doi: 10.1111/exd.13415

15. Li X, Qian H, Sogame R, Hirako Y, Tsuruta D, Ishii N, et al. Integrin $\beta 4$ is a major target antigen in pure ocular mucous membrane pemphigoid. Eur $J$ Dermatol. (2016) 26:247-53. doi: 10.1684/ejd.2016.2772

16. Amber KT, Murrell DF, Schmidt E, Joly P, Borradori L. Autoimmune subepidermal bullous diseases of the skin and mucosae: clinical features, diagnosis, and management. Clin Rev Allergy Immunol. (2017) 381:320-6. doi: 10.1007/s12016-017-8633-4

17. Hayakawa T, Furumura M, Fukano H, Li X, Ishii N, Hamada T, et al. Diagnosis of oral mucous membrane pemphigoid by means of combined serologic testing. Oral Surg Oral Med Oral Pathol Oral Radiol. (2014) 117:483-96. doi: 10.1016/j.oooo.2013.12.402

18. Kamaguchi $M$, Iwata $H$, Ujiie $H$, Izumi $K$, Natsuga $K$, Nishie $W$, et al. Oral mucosa is a useful substrate for detecting autoantibodies of mucous membrane pemphigoid. Br J Dermatol. (2017) 178:e119-21. doi: $10.1111 /$ bjd. 15925 
19. Taylor J, McMillan R, Shephard M, Setterfield J, Ahmed R, Carrozzo M, et al. World Workshop on oral medicine VI: a systematic review of the treatment of mucous membrane pemphigoid. Oral Surg Oral Med Oral Pathol Oral Radiol. (2015) 120:161-71.e20. doi: 10.1016/j.oooo.2015.01.024

20. Tsunoda K, Ota T, Aoki M, Yamada T, Nagai T, Nakagawa T, et al. Induction of pemphigus phenotype by a mouse monoclonal antibody against the aminoterminal adhesive interface of desmoglein 3. J Immunol. (2003) 170:2170-8. doi: 10.4049/jimmunol.170.4.2170

21. Ishii K, Harada R, Matsuo I, Shirakata Y, Hashimoto K, Amagai M. In vitro keratinocyte dissociation assay for evaluation of the pathogenicity of antidesmoglein $3 \mathrm{IgG}$ autoantibodies in pemphigus vulgaris. J Invest Dermatol. (2005) 124:939-46. doi: 10.1111/j.0022-202X.2005.23714.x

22. Iwata $\mathrm{H}$, Bieber $\mathrm{K}$, Hirose $\mathrm{M}$, Ludwig RJ. Animal models to investigate pathomechanisms and evaluate novel treatments for autoimmune bullous dermatoses. Curr Pharm Des. (2015) 21:2422-39. doi: 10.2174/1381612821666150316122502

23. Ludwig RJ, Vanhoorelbeke K, Leypoldt F, Kaya Z, Bieber K, McLachlan SM, et al. Mechanisms of autoantibody-induced pathology. Front Immunol. (2017) 8:603. doi: 10.3389/fimmu.2017.00603

24. Kamaguchi M, Iwata H, Nishie W, Toyonaga E, Ujiie H, Natsuga K, et al. The direct binding of collagen XVII and collagen IV is disrupted by pemphigoid autoantibodies. Lab Invest. (2018) 99:48-57. doi: 10.1038/s41374-018-0113-9

25. Scully C, Muzio Lo L. Oral mucosal diseases: mucous membrane pemphigoid. Br J Oral Maxillofac Surg. (2008) 46:358-66. doi: 10.1016/j.bjoms.2007. 07.200

26. Rose C, Schmidt E, Kerstan A, Thoma-Uszynski S, Wesselmann U, Käsbohrer $\mathrm{U}$, et al. Histopathology of anti-laminin 5 mucous membrane pemphigoid. $J$ Am Acad Dermatol. (2009) 61:433-40. doi: 10.1016/j.jaad.2009.02.012

27. Kamaguchi M, Iwata H, Ujiie I, Ujiie H, Sato J, Kitagawa Y, et al. Direct immunofluorescence using non-lesional buccal mucosa in mucous membrane pemphigoid. Front Med. (2018) 5:20. doi: 10.3389/fmed.2018.00020

28. Benoit S, Scheurlen M, Goebeler M, Stoevesandt J. Structured diagnostic approach and risk assessment in mucous membrane pemphigoid with oesophageal involvement. Acta Derm Venerol. (2018) 98:660-6. doi: 10.2340/00015555-2938

29. Carrozzo M, Cozzani E, Broccoletti R, Carbone M, Pentenero M, Arduino $\mathrm{P}$, et al. Analysis of antigens targeted by circulating IgG and IgA antibodies in patients with mucous membrane pemphigoid predominantly affecting the oral cavity. J Periodontol. (2004) 75:1302-8. doi: 10.1902/jop.2004.75.10.1302

30. Sarret Y, Hall R, Cobo LM, Thivolet J, Patton DL, Woodley DT. Salt-split human skin substrate for the immunofluorescent screening of serum from patients with cicatricial pemphigoid and a new method of immunoprecipitation with IgA antibodies. J Am Acad Dermatol. (1991) 24:952-8. doi: 10.1016/0190-9622(91)70152-R

31. Gammon WR, Fine JD, Forbes M, Briggaman RA. Immunofluorescence on split skin for the detection and differentiation of basement membrane zone autoantibodies. J Am Acad Dermatol. (1992) 27:79-87. doi: 10.1016/0190-9622(92)70161-8

32. Zillikens D, Mascaro JM, Rose PA, Liu Z, Ewing SM, Caux F, et al. A highly sensitive enzyme-linked immunosorbent assay for the detection of circulating anti-BP180 autoantibodies in patients with bullous pemphigoid. J Invest Dermatol. (1997) 109:679-83. doi: 10.1111/1523-1747.ep123 38088

33. Kobayashi M, Amagai M, Kuroda-Kinoshita K, Hashimoto T, Shirakata Y, Hashimoto K, et al. BP180 ELISA using bacterial recombinant NC16a protein as a diagnostic and monitoring tool for bullous pemphigoid. J Dermatol Sci. (2002) 30:224-32. doi: 10.1016/S0923-1811(02)00109-3

34. Sakuma-Oyama Y, Powell AM, Oyama N, Albert S, Bhogal BS, Black MM. Evaluation of a BP180-NC16a enzyme-linked immunosorbent assay in the initial diagnosis of bullous pemphigoid. Br J Dermatol. (2004) 151:126-31. doi: 10.1111/j.1365-2133.2004.06082.x

35. Sitaru C, Dähnrich C, Probst C, Komorowski L, Blöcker I, Schmidt E, et al. Enzyme-linked immunosorbent assay using multimers of the 16th non-collagenous domain of the BP180 antigen for sensitive and specific detection of pemphigoid autoantibodies. Exp Dermatol. (2007) 16:770-7. doi: 10.1111/j.1600-0625.2007.00592.x

36. Fujio Y, Kojima K, Hashiguchi M, Wakui M, Murata M, Amagai M, et al. Validation of chemiluminescent enzyme immunoassay in detection of autoantibodies in pemphigus and pemphigoid. J Dermatol Sci. (2017) 85:208-15. doi: 10.1016/j.jdermsci.2016.12.007

37. Horváth ON, Varga R, Kaneda M, Schmidt E, Ruzicka T, Sárdy M. Diagnostic performance of the "MESACUP anti-Skin profile TEST." Eur J Dermatol. (2016) 26:56-63. doi: 10.1684/ejd.2015.2692

38. Izumi K, Nishie W, Mai Y, Wada $M$, Natsuga $K$, Ujiie $H$, et al. Autoantibody profile differentiates between inflammatory and noninflammatory bullous pemphigoid. J Invest Dermatol. (2016) 136:2201-10. doi: 10.1016/j.jid.2016.06.622

39. Ali S, Kelly C, Challacombe SJ, Donaldson AN, Dart JK, Gleeson M, et al. Salivary IgA and IgG antibodies to bullous pemphigoid 180 noncollagenous domain 16 a as diagnostic biomarkers in mucous membrane pemphigoid. $\mathrm{BrJ}$ Dermatol. (2016) 174:1022-9. doi: 10.1111/bjd.14351

40. Endo H, Rees TD, Allen EP, Kuyama K, Aoki S, Yamamoto H, et al. A staband-roll biopsy technique to maintain gingival epithelium for desquamative gingivitis. J Periodontol. (2014) 85:802-9. doi: 10.1902/jop.2014.130428

41. Shimanovich I, Nitz JM, Zillikens D. Multiple and repeated sampling increases the sensitivity of direct immunofluorescence testing for the diagnosis of mucous membrane pemphigoid. J Am Acad Dermatol. (2017) 77:700-3. doi: 10.1016/j.jaad.2017.05.016

42. Shimanovich I, Nitz JM, Witte M, Zillikens D, Rose C. Immunohistochemical diagnosis of mucous membrane pemphigoid. J Oral Pathol Med. (2018) 47:613-9. doi: 10.1111/jop.12732

43. Goletz S, Probst C, Komorowski L, Schlumberger W, Fechner K, van Beek $\mathrm{N}$, et al. Sensitive and specific assay for the serological diagnosis of antilaminin 332 mucous membrane pemphigoid. Br J Dermatol. (2018) 180:14956. doi: 10.1111/bjd.17202

44. Bernard P, Antonicelli F, Bedane C, Joly P, Le Roux-Villet C, DuvertLehembre S, et al. Prevalence and clinical significance of anti-laminin 332 autoantibodies detected by a novel enzyme-linked immunosorbent assay in mucous membrane pemphigoid. JAMA Dermatol. (2013) 149:533-40. doi: 10.1001/jamadermatol.2013.1434

45. Chiorean R, Danescu S, Virtic O, Mustafa MB, Baican A, Lischka A, et al. Molecular diagnosis of anti-laminin 332 (epiligrin) mucous membrane pemphigoid. Orphanet J Rare Dis. (2018) 13:111. doi: 10.1186/s13023-018-0855-x

46. Nie Z, Hashimoto T. IgA antibodies of cicatricial pemphigoid sera specifically react with C-terminus of BP180. J Invest Dermatol. (1999) 112:254-5. doi: 10.1046/j.1523-1747.1999.00501.x

47. Schmidt E, Kromminga A, Mimietz S, Leinfelder U, Sitaru C, Bröcker $\mathrm{EB}$, et al. A highly sensitive and simple assay for the detection of circulating autoantibodies against full-length bullous pemphigoid antigen 180. J Autoimmun. (2002) 18:299-309. doi: 10.1006/jaut.2002.0589

48. Izumi K, Nishie W, Mai Y, Ujiie H, Iwata H, Natsuga K, et al. Detection of mucous membrane pemphigoid autoantibodies by full-length BP180 enzyme-linked immunosorbent assay. J Dermatol Sci. (2017) 88:247-8. doi: 10.1016/j.jdermsci.2017.07.005

49. Kamaguchi M, Iwata $H$, Miyauchi $T$, Ujiie H, Ujiie I, Nomura $T$, et al. The identification of autoantigens in mucous membrane pemphigoid using immortalized oral mucosal keratinocytes. J Oral Pathol Med. (2018) 48:60-7. doi: $10.1111 /$ jop. 12780

50. Emtenani S, Yuan H, Lin C, Pan M, Hundt JE, Schmidt E, et al. Normal human skin is superior to monkey esophagus substrate for detection of circulating BP180-NC16A-specific immunoglobulin G antibodies in bullous pemphigoid. Br J Dermatol. (2018). doi: 10.1111/bjd.17313. [Epub ahead of print].

51. Ong HS, Setterfield JF, Minassian DC, Dart JK. Mucous membrane pemphigoid with ocular involvement: the clinical phenotype and its relationship to direct immunofluorescence findings. Ophthalmology (2018) 125:496-504. doi: 10.1016/j.ophtha.2017.10.004

52. Thorne JE, Anhalt GJ, Jabs DA. Mucous membrane pemphigoid and pseudopemphigoid. Ophthalmology (2004) 111:45-52. doi: 10.1016/j.ophtha.2003.03.001

53. Bernauer W, Elder MJ, Leonard JN, Wright P, Dart JK. The value of biopsies in the evaluation of chronic progressive conjunctival cicatrisation. Graefes Arch Clin Exp Ophthalmol. (1994) 232:533-7. doi: 10.1007/BF00181996

54. Helander SD, Rogers RS. The sensitivity and specificity of direct immunofluorescence testing in disorders of mucous membranes. J Am Acad Dermatol. (1994) 30:65-75. doi: 10.1016/S0190-9622(94)70010-9 
55. Setterfield J, Shirlaw PJ, Kerr-Muir M, Neill S, Bhogal BS, Morgan P, et al. Mucous membrane pemphigoid: a dual circulating antibody response with IgG and IgA signifies a more severe and persistent disease. $\mathrm{Br} J$ Dermatol. (1998) 138:602-10. doi: 10.1046/j.1365-2133.1998.02168.x

56. Kridin K. Peripheral eosinophilia in bullous pemphigoid: prevalence and influence on the clinical manifestation. Br J Dermatol. (2018) 179:1141-7. doi: $10.1111 /$ bjd.16679

57. Mendonça FMI, Martín-Gutierrez FJ, Ríos-Martín JJ, Camacho-Martinez F. Three cases of bullous pemphigoid associated with dipeptidyl peptidase4 inhibitors - one due to linagliptin. Dermatology (2016) 232:249-53. doi: $10.1159 / 000443330$

58. Gaudin O, Seta V, Alexandre M, Bohelay G, Aucouturier F, MignotGrootenboer S, et al. Gliptin accountability in mucous membrane pemphigoid induction in 24 out of 313 patients. Front Immunol. (2018) 9:1030. doi: 10.3389/fimmu.2018.01030

59. Ujiie H, Muramatsu K, Mushiroda T, Ozeki T, Miyoshi H, Iwata $H$, et al. HLA-DQB1*03:01 as a biomarker for genetic susceptibility to bullous pemphigoid induced by DPP-4 inhibitors. J Invest Dermatol. (2017) 138:12014. doi: 10.1016/j.jid.2017.11.023

60. Ahmed AR, Foster S, Zaltas M, Notani G, Awdeh Z, Alper CA, et al. Association of DQw7 (DQB1*0301) with ocular cicatricial pemphigoid. Proc Natl Acad Sci USA. (1991) 88:11579-82. doi: 10.1073/pnas.88.24.11579

61. Setterfield J, Theron J, Vaughan RW, Welsh KI, Mallon E, Wojnarowska F, et al. Mucous membrane pemphigoid: HLA-DQB1*0301 is associated with all clinical sites of involvement and may be linked to antibasement membrane IgG production. Br J Dermatol. (2001) 145:406-14. doi: 10.1046/j.1365-2133.2001.04380.x

62. Oyama N, Setterfield JF, Powell AM, Sakuma-Oyama Y, Albert S, Bhogal BS, et al. Bullous pemphigoid antigen II (BP180) and its soluble extracellular domains are major autoantigens in mucous membrane pemphigoid: the pathogenic relevance to HLA class II alleles and disease severity. $\mathrm{Br} J$ Dermatol. (2006) 154:90-8. doi: 10.1111/j.1365-2133.2005.06998.x

63. Hübner F, Setterfield J, Recke A, Zillikens D, Schmidt E, Dart J, et al. HLA alleles in British Caucasians with mucous membrane pemphigoid. Eye (2018) 32:1540-1. doi: 10.1038/s41433-018-0092-5

64. Hofmann S, Thoma-Uszynski S, Hunziker T, Bernard P, Koebnick C, Stauber A, et al. Severity and phenotype of bullous pemphigoid relate to autoantibody profile against the $\mathrm{NH} 2$ - and $\mathrm{COOH}$-terminal regions of the BP180 ectodomain. J Invest Dermatol. (2002) 119:1065-73. doi: 10.1046/j.1523-1747.2002.19529.x

65. Clapé A, Muller C, Gatouillat G, Le Jan S, Barbe C, Pham BN, et al. Mucosal involvement in bullous pemphigoid is mostly associated with disease severity and to absence of anti-BP230 autoantibody. Front Immunol. (2018) 9:479. doi: 10.3389/fimmu.2018.00479

66. Heppe EN, Tofern S, Schulze FS, Ishiko A, Shimizu A, Sina C, et al. Experimental laminin 332 mucous membrane pemphigoid critically involves $\mathrm{C} 5 \mathrm{aR} 1$ and reflects clinical and immunopathological characteristics of the human disease. J Invest Dermatol. (2017) 137:1709-18 doi: 10.1016/j.jid.2017.03.037

67. Lazarova Z, Yee C, Darling T, Briggaman RA, Yancey KB. Passive transfer of anti-laminin 5 antibodies induces subepidermal blisters in neonatal mice. $J$ Clin Invest. (1996) 98:1509-18. doi: 10.1172/JCI118942

68. Lazarova Z, Hsu R, Briggaman RA, Yancey KB. Fab fragments directed against laminin 5 induce subepidermal blisters in neonatal mice. Clin Immunol. (2000) 95:26-32. doi: 10.1006/clim.2000.4845

69. Lazarova Z, Hsu R, Yee C, Yancey KB. Human anti-laminin 5 autoantibodies induce subepidermal blisters in an experimental human skin graft model. $J$ Invest Dermatol. (2000) 114:178-84. doi: 10.1046/j.1523-1747.2000.00829.x

70. Liu Z, Diaz LA, Troy JL, Taylor AF, Emery DJ, Fairley JA, et al. A passive transfer model of the organ-specific autoimmune disease, bullous pemphigoid, using antibodies generated against the hemidesmosomal antigen, BP180. J Clin Invest. (1993) 92:2480-8. doi: 10.1172/JCI116856
71. Nishie W, Sawamura D, Goto M, Ito K, Shibaki A, McMillan JR, et al. Humanization of autoantigen. Nat Med. (2007) 13:378-83. doi: 10.1038/nm1496

72. Ujiie H, Shibaki A, Nishie W, Sawamura D, Wang G, Tateishi Y, et al. A novel active mouse model for bullous pemphigoid targeting humanized pathogenic antigen. J Immunol. (2010) 184:2166-74. doi: 10.4049/jimmunol.0903101

73. Schulze FS, Beckmann T, Nimmerjahn F, Ishiko A, Collin M, Köhl J, et al. Fc $\gamma$ receptors III and IV mediate tissue destruction in a novel adult mouse model of bullous pemphigoid. Am J Pathol. (2014) 184:2185-96. doi: 10.1016/j.ajpath.2014.05.007

74. Imanishi A, Imanishi $\mathrm{H}$, Hiroyasu S, Ozawa $\mathrm{T}$, Koga $\mathrm{H}$, Ishii $\mathrm{N}$, et al. Anti-BP180-type mucous membrane pemphigoid immunoglobulin $G$ shows heterogeneity of internalization of BP180/collagen XVII into keratinocyte cytoplasm. Med Mol Morphol. (2015) 49:89-97. doi: 10.1007/s00795-015-0128-X

75. Kitajima Y, Inoue S, Yaoita H. Effects of pemphigus antibody on the regeneration of cell-cell contact in keratinocyte cultures grown in low to normal $\mathrm{Ca}++$ concentration. I Invest Dermatol. (1987) 89:167-71. doi: 10.1111/1523-1747.ep12470554

76. Iwata H, Kamio N, Aoyama Y, Yamamoto Y, Hirako Y, Owaribe K, et al. IgG from patients with bullous pemphigoid depletes cultured keratinocytes of the $180-\mathrm{kDa}$ bullous pemphigoid antigen (Type XVII collagen) and weakens cell attachment. J Invest Dermatol. (2009) 129:919-26. doi: 10.1038/jid.2008.305

77. Iwata H, Kitajima Y. Bullous pemphigoid: role of complement and mechanisms for blister formation within the lamina lucida. Exp Dermatol. (2013) 22:381-5. doi: 10.1111/exd.12146

78. Liu Z, Giudice GJ, Swartz SJ, Fairley JA, Till GO, Troy JL, et al. The role of complement in experimental bullous pemphigoid. J Clin Invest. (1995) 95:1539-44. doi: 10.1172/JCI117826

79. Liu Z, Giudice GJ, Zhou X, Swartz SJ, Troy JL, Fairley JA, et al. A major role for neutrophils in experimental bullous pemphigoid. J Clin Invest. (1997) 100:1256-63. doi: 10.1172/JCI119639

80. Iwata $H$, Ujiie $H$. Complement-independent blistering mechanisms in bullous pemphigoid. Exp Dermatol. (2017) 26:1235-9. doi: 10.1111/exd. 13367

81. Kamaguchi $M$, Iwata $H$, Ujiie $H$, Natsuga $K$, Nishie W, Kitagawa $Y$, et al. High expression of collagen XVII compensates for its depletion induced by pemphigoid IgG in the oral mucosa. J Invest Dermatol. (2018) 138:1707-15. doi: 10.1016/j.jid.2018.03.002

82. Wada M, Nishie W, Ujiie H, Izumi K, Iwata H, Natsuga K, et al. Epitopedependent pathogenicity of antibodies targeting a major bullous pemphigoid autoantigen collagen XVII/BP180. J Invest Dermatol. (2016) 136:938-46. doi: 10.1016/j.jid.2015.11.030

83. Imafuku $K$, Iwata $H$, Kamaguchi $M$, Izumi $K$, Natsuga $K$, Ujiie $H$, et al. Autoantibodies of non-inflammatory bullous pemphigoid hardly deplete type XVII collagen of keratinocytes. Exp Dermatol. (2017) 381:320. doi: 10.1111/exd.13331

84. Di Zenzo G, Grosso F, Terracina M, Mariotti F, De Pità O, Owaribe K, et al. Characterization of the anti-BP180 autoantibody reactivity profile and epitope mapping in bullous pemphigoid patients. J Invest Dermatol. (2004) 122:103-10. doi: 10.1046/j.0022-202X.2003.22126.x

Conflict of Interest Statement: The authors declare that the research was conducted in the absence of any commercial or financial relationships that could be construed as a potential conflict of interest.

Copyright (c) 2019 Kamaguchi and Iwata. This is an open-access article distributed under the terms of the Creative Commons Attribution License (CC BY). The use, distribution or reproduction in other forums is permitted, provided the original author(s) and the copyright owner(s) are credited and that the original publication in this journal is cited, in accordance with accepted academic practice. No use, distribution or reproduction is permitted which does not comply with these terms. 